\title{
Diffusion Coatings for Corrosion Resistant Components in Coal Gasification Systems
}

Quarterly Technical Progress Report 4

Covering the period April 1, 2004 through June 30, 2004

Prepared by:

Gopala N. Krishnan, Ripudaman Malhotra, Esperanza Alvarez, Kai-Hung Lau and Angel Sanjurjo

SRI International, 333 Ravenswood Avenue, Menlo Park, CA 94025

Prepared for:

U.S. Department of Energy

National Energy Technology Center

P. O. Box 10940

Pittsburgh, PA 15236

Attention: Mr. Richard Read

SRI Project PYU-13063

DOE Contract No.: DE-FC26-03NT41616 


\section{DISCLAIMER}

This report was prepared as an account of work sponsored by an agency of the United States Government. Neither the United States Government nor any agency thereof, nor any of their employees, makes any warranty, express or implied, or assumes any legal liability or responsibility for the accuracy, completeness, or usefulness of any information, apparatus, product, or process disclosed, or represents that its use would not infringe privately owned rights. Reference herein to any specific commercial product, process, or service by trade name, trademark, manufacturer, or otherwise does not necessarily constitute or imply endorsement, recommendation, or favoring by the United States Government or any agency thereof. The views and opinions of authors expressed herein do not necessarily state or reflect those of the United States Government or any agency thereof. 


\begin{abstract}
Heat-exchangers, particle filters, turbines, and other components in integrated coal gasification combined cycle system must withstand the highly sulfiding conditions of the high temperature coal gas over an extended period of time. The performance of components degrades significantly with time unless expensive high alloy materials are used. Deposition of a suitable coating on a low cost alloy may improve is resistance to such sulfidation attack and decrease capital and operating costs. The alloys used in the gasifier service include austenitic and ferritic stainless steels, nickel-chromium-iron alloys, and expensive nickel-cobalt alloys.

During this reporting period we coated coupons of selected alloy steels with diffusion coatings of $\mathrm{Cr}$ and $\mathrm{Al}$, as well as with titanium and tantalum nitrides. The coated samples were analyzed for their surface composition. In several instances, the samples were also cut to determine the depth profile of the coating.

Several of the early runs did not yield uniform or deep enough coatings and hence a significant portion of the effort in this period was devoted fixing the problems with our fluidized bed reactor. Before the end of the quarter we had prepared a number of samples, many of them in duplicates, and sent one set to Wabash River Energy Laboratory for them to install in their gasifier. The gasifier was undergoing a scheduled maintenance and thus presented an opportunity to place some of our coupons in the stream of an operating gasifier. The samples submitted included coated and uncoated pairs of different alloys. .
\end{abstract}




\section{TABLE OF CONTENTS}

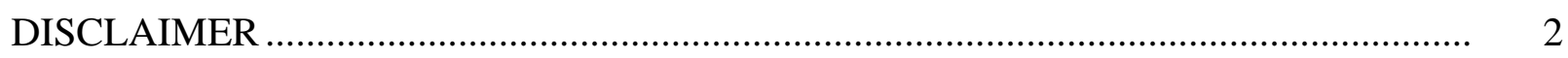

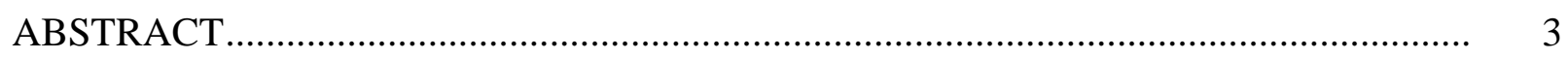

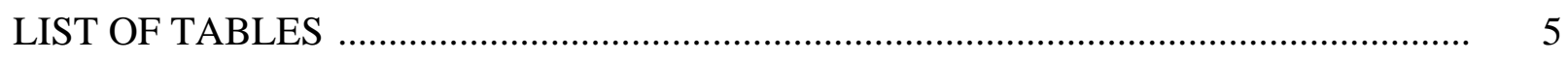

LIST OF FIGURES ...................................................................................... 5

EXECUTIVE SUMARY .................................................................................. 6

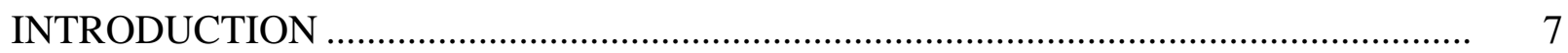

COATING COMPOSITIONS ....................................................................... 8

COATING METHOD

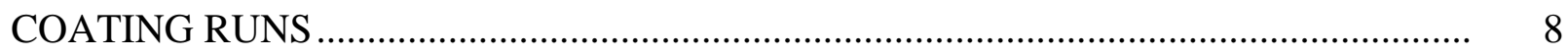

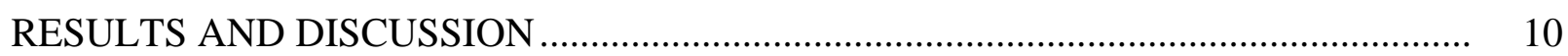

CONCLUSIONS AND FUTURE WORK ............................................................... 14 


\section{LIST OF TABLES}

1. Summary of coating runs ............................................................................

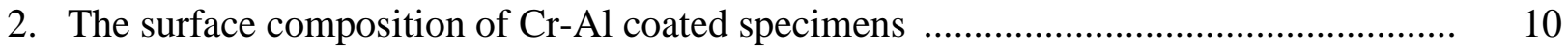

3. Elemental composition inside the porous SS316 frit ........................................... 12

4. Samples sent for Gasifier Exposure Tests ...................................................................

\section{LIST OF FIGURES}

1. Simplified schematic of a fluidized bed reactor with RF heating .............................. 9

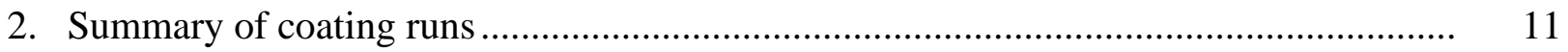

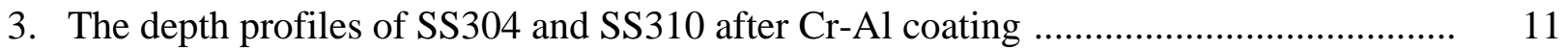

4. SEM image of the porous SS 316 frit ................................................................ 12

5. A magnified image of porous SS frit and the distribution of Ti inside the frit.............. 13 


\section{EXECUTIVE SUMMARY}

Advanced coal gasification systems such as integrated coal gasification combined cycle (IGCC) processes offer many advantages over conventional pulverized coal combustors. Heat-exchangers, filters, turbines, and other components in IGCC plants are often must withstand the highly sulfiding conditions at high temperatures. In collaboration with U.S. Department of Energy and Conoco/ Phillips, we are developing corrosion-resistant coatings for high temperature components in IGCC systems.

Wabash River Energy Laboratory (WREL), a subsidiary of Conoco/Phillips operates an IGCC system at Terre Haute, IN. The need for corrosion resistant coatings exists in two areas: (1) the tube sheet of a heat exchanger that is immediately downstream of the gasifier, and (2) porous metal particulate filter, which is downstream of the heat exchanger. These components operate at gas streams containing as much as $2 \% \mathrm{H}_{2} \mathrm{~S}$. The temperatures of the heat exchanger and the metal filters are $\sim 1000^{\circ}$ and $\sim 370^{\circ} \mathrm{C}$, respectively. A protective metal or ceramic coating that can resist sulfidation corrosion will extend the life-time of these components and reduce maintenance.

Although the specifications of the material components used in the gasifier system are proprietary, alloys used in the gasifier service include austenitic stainless steels such as 304 alloy, ferritic stainless steels such as 405 and 410 alloys, nickel-based alloys such as Incoloy 800, and nickel-cobalt alloys such as HR160.

During this reporting period we coated coupons of selected alloy steels with diffusion coatings of $\mathrm{Cr}$ and $\mathrm{Al}$, as well as with titanium and tantalum nitrides. The coated samples were analyzed for their surface composition. In several instances, the samples were also cut to determine the depth profile of the coating.

Several of the early runs did not yield uniform or deep enough coatings and hence a significant portion of the effort in this period was devoted fixing the problems with our fluidized bed reactor. Before the end of the quarter we had prepared a number of samples, many of them in duplicates, and sent one set to Wabash River Energy Laboratory for them to install in their gasifier. The gasifier was undergoing a scheduled maintenance and thus presented an opportunity to place some of our coupons in the stream of an operating gasifier. The samples submitted included coated and uncoated pairs of different alloys. 


\section{INTRODUCTION}

Heat-exchangers, filters, turbines, and other components in coal-fired power plants are often have to withstand demanding conditions of high temperatures and pressure differentials. Further, the components are exposed to corrosive gases and particulates that can erode the material and degrade their performance. In collaboration with U.S. Department of Energy and Conoco/Phillips, SRI International recently embarked on a project to develop corrosion-resistant coatings for coal-fired power plant applications. Specifically, we are seeking to develop coatings that would prevent the corrosion in the tube-sheet of the high temperature heat recovery unit of a coal gasification power plant operated by Wabash River Energy Laboratory (WREL) in Terre Haute, IN. This corrosion is the leading cause of the unscheduled downtime at the plant, and hence success in this project will directly impact the plant availability and its operating costs. Coatings that are successfully developed for this application will find use in similar situation in other coal-fired power plants.

Although the specifications of the material components used in the gasifier system are proprietary, alloys used in the gasifier service include austenitic stainless steels such as 304 alloy, ferritic stainless steels such as 405 and 410 alloys, nickel-based alloys such as Incoloy 800, and nickel-cobalt alloys such as HR160.

Based on a brief review of the published literature reported earlier, we selected the following coating compositions: (1) Cr diffusion coatings, (2) aluminum diffusion coatings, and (3) titanium, tantalum, and silicon coatings either nitrided or in combination with other coatings.

We have developed a fluidized-bed chemical vapor deposition technique to coat several metal and ceramic compositions on powders, tubes, and sheets. This technique is more rapid than pack cementation used for chromizing and aluminizing metal parts. It is relatively low in cost in comparison with conventional chemical vapor deposition technique as the precursors are generated in the fluidized bed reactor. Because of excellent mass and heat transfer characteristics of the fluidized bed, the rate of coating can be rapid. The technique can be used to coat complex shapes because the chemical vapor deposition technique is not limited to line-of-sight. 


\section{COATING COMPOSITIONS}

We selected several alloy steels that are typically used as components in a coal gasifier. They include nickel-based alloys such as HR-160, Incoloy 800 and stainless steels such as SS304, SS316, SS405, and SS410. All these alloys degrade when exposed to high levels of $\mathrm{H}_{2} \mathrm{~S}$ in a high temperature coal gas and require additional protective coatings. For the initial tests, we selected the stainless steel substrates. Because stainless steels are less expensive than the nickel-based alloys, corrosion resistant coating will provide the most benefit. We also selected diffusion coatings of $\mathrm{Cr}$ and $\mathrm{Al}$ and surface coatings containing silicon nitride and titanium nitride or titanium and tantalum oxides. Coatings that have high levels of $\mathrm{Cr}$ and $\mathrm{Al}$ are expected to provide sulfidation resistance. Coatings of $\mathrm{Ti}, \mathrm{Ta}$ and $\mathrm{Si}$ may provide a compact oxide layer that resists the ingress of $\mathrm{S}$ into the alloy. Porous metal tubes are used at WREL as particulate filters at WREL and hence, we also selected porous 316 stainless steel frit for coating deposition.

\section{COATING METHOD}

SRI International's fluidized-bed CVD technique has been described in detail in earlier reports. Briefly, volatile metal halides are formed in situ in a fluidized bed reactor by reaction of a metal powder (e.g. $\mathrm{Cr}, \mathrm{Si}$, or $\mathrm{Ti}$ ) with $\mathrm{HCl}$. The metal chloride vapors decompose on the substrate to form a metallic coating. Simplified schematic diagram of a fluidized bed reactor is shown in Figure 1. The fluidized bed is either heated using an electrical resistance furnace or by RF induction on a graphite susceptor. The fluidized bed, with its high mass and heat transfer characteristics allow uniform temperature and rapid deposition rates.

\section{COATING RUNS}

For depositing $\mathrm{Cr}-\mathrm{Al}$ coating, the specimens were immersed in a fluidized bed of a mixture of alumina powder, chromium powder, and $\mathrm{Cr}-\mathrm{Al}$ alloy powder. The bed was fluidized with a stream of $\operatorname{Ar}(\mathrm{g})$ and $\mathrm{H}_{2}(\mathrm{~g})$. The bed was heated to a temperature in the range $960^{\circ}$ to $1000^{\circ} \mathrm{C}$ and $\mathrm{HCl}(\mathrm{g})$ was admitted to generate volatile chromium and aluminum chloride species which then decompose or reduce on the specimen. Deposition durations were typically about $3 \mathrm{~h}$ each. We used a bed of Si or Ti powder mixed with alumina to provide coatings containing $\mathrm{Si}$ or $\mathrm{Ti}$. $\mathrm{TaCl}_{5}$ powder was used as the precursor for Ta-based coatings. Table 1 summarizes the different coating experiments we undertook during this period. 


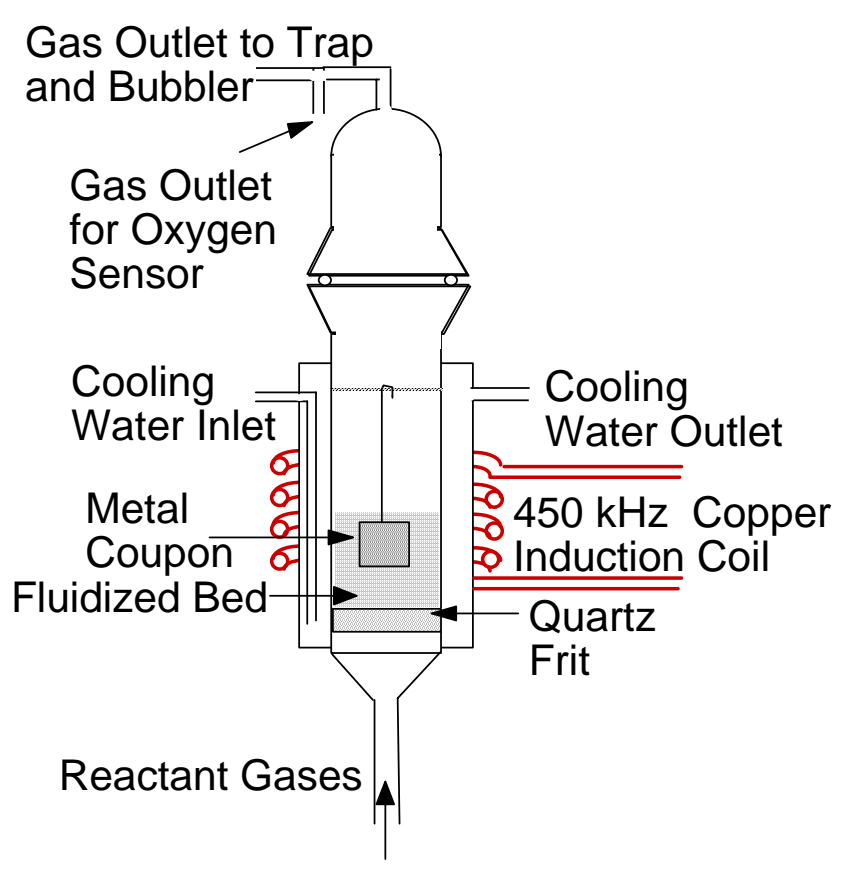

Figure 1. Simplified schematic of a fluidized bed reactor with RF heating.

Table 1

SUMMARY OF COATING RUNS

\begin{tabular}{|c|c|c|c|c|c|}
\hline Run. No & Substrate & $\begin{array}{c}\text { No. of } \\
\text { Coupons }\end{array}$ & Coating & Coating depth & $\begin{array}{c}\text { Surface Cr } \\
\text { Concentraton }\end{array}$ \\
\hline 39 & SS 410 & 1 & $\mathrm{Cr}$ & 10 & 76.8 \\
\hline 40 & SS 410 & 1 & $\mathrm{Cr}$ & 5 & 60 \\
\hline 41 & SS 316L & 3 & $\mathrm{Cr}$ & & $32.3^{1}$ \\
\hline 42 & SS 304 & 1 & $\mathrm{Cr}$ & 5 & 62 \\
\hline 42 & SS 410 & 1 & $\mathrm{Cr}$ & 10 & 62 \\
\hline 43 & SS 304 & 1 & $\mathrm{Cr}$ & 5 & 33.5 \\
\hline 43 & SS 405 & 1 & $\mathrm{Cr}$ & 20 & 16 \\
\hline 43 & SS 410 & 1 & $\mathrm{Cr}$ & 3 to 5 & 28 \\
\hline 43 & IN-800 & 1 & $\mathrm{Cr}$ & 4 to 5 & 18 \\
\hline 46 & SS 405 & 3 & $\mathrm{Cr}$ & & 20 \\
\hline 47 & SS 405 & 1 & $\mathrm{Ti} / \mathrm{Ta}$ & & \\
\hline 47 & SS 316L & 1 & $\mathrm{Ti} / \mathrm{Ta}$ & 3 & 2 \\
\hline 48 & SS 410 & 1 & $\mathrm{Cr}$ & 20 (plateau) & 70 \\
\hline 50 & SS 410 & & $\mathrm{Si} / \mathrm{TiN}$ & & \\
\hline
\end{tabular}




\section{RESULTS AND DISCUSSION}

The coated samples were examined by various techniques such as scanning electron microscope (SEM), energy-dispersive X-ray analysis (EDX), and X-ray fluorescence (XRF). The surface composition of Cr-Al-coated coupons is shown in Table 2. The data show that the surface is enriched in $\mathrm{Cr}-\mathrm{Al}$, except in the case of IN 800 alloy, which is a nickel-rich alloy.

\section{Table 2}

THE SURFACE COMPOSITION OF Cr-AI COATED SPECIMENS

\begin{tabular}{|l|c|c|c|c|c|}
\hline & & \multicolumn{4}{|c|}{ Surface Composition (Wt\%) } \\
\hline \multicolumn{1}{|c|}{ Alloy } & Run No. & Al & Cr & Fe & Ni \\
\hline SS304 & 42 & 5.2 & 61.6 & 24.2 & 8.9 \\
\hline SS316 & 41 & 5.4 & 32.3 & 52.1 & 8.1 \\
\hline SS405 & 44 & 2.9 & 68.4 & 28.7 & 0 \\
\hline SS410 & 42 & 2.8 & 61.8 & 35.4 & 0 \\
\hline IN 800 & 44 & 12.0 & 18.0 & 42.4 & 17.5 \\
\hline
\end{tabular}

We also measured the distribution of $\mathrm{Cr}$ and $\mathrm{Al}$ diffused into the samples. The depth profiles of SS 216 and SS 410 after coating with $\mathrm{Cr}$-Al coated are shown in Figure 2. The data indicate that the surface concentration of $\mathrm{Cr}$ was high, but the diffusion depth was limited.

The $\mathrm{Si}_{3} \mathrm{~N}_{4}$-TiN coated sample was also examined by scanning electron microscopy. The distributions of $\mathrm{Si}$ and $\mathrm{Ti}$ inside the specimen were determined by the energy-dispersive X-ray analysis. Figure 3 illustrates the SEM image along with $\mathrm{Fe}, \mathrm{Cr}$, and Ti maps in the examined area. In this map the brightness of the image is proportional to the concentration of the element at that point. As expected, the elemental maps show that the surface was enriched in $\mathrm{Ti}$, which is consistent with the fact that Ti or TiN cannot diffuse into the stainless steel. The TiN coating appears to be dense and has a thickness of about $2 \mu \mathrm{m}$.

Figure 4 and Table 3 show the SEM image of the porous SS316 frit and the elemental composition inside the frit. They indicate that $\mathrm{Si}$ and Ti-based coatings are present even in the interior of the porous frit confirming that the fluidized bed chemical vapor deposition is capable of coating inside a porous material. 


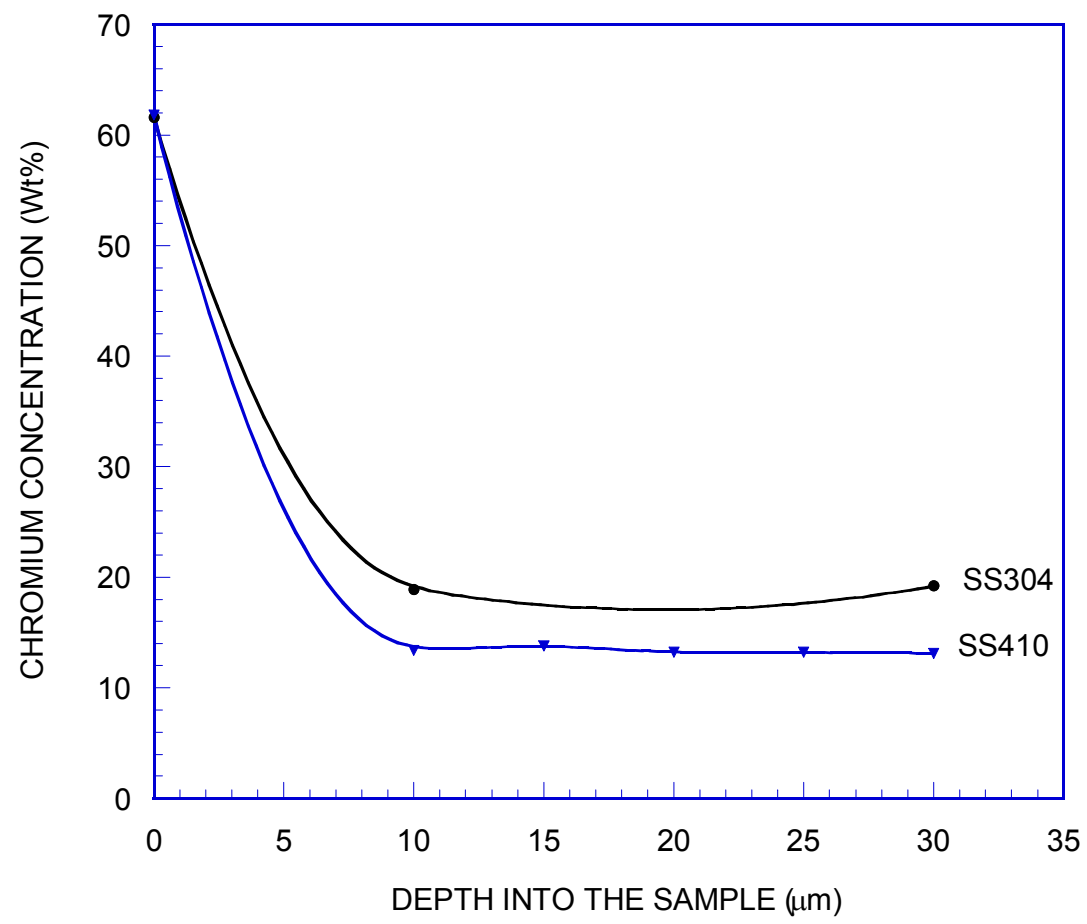

Figure 2. The depth profiles of SS304 and SS310 after Cr-Al coating.

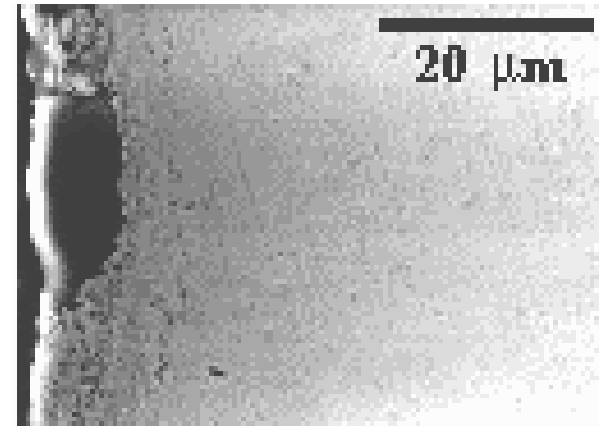

(a) SEM Image

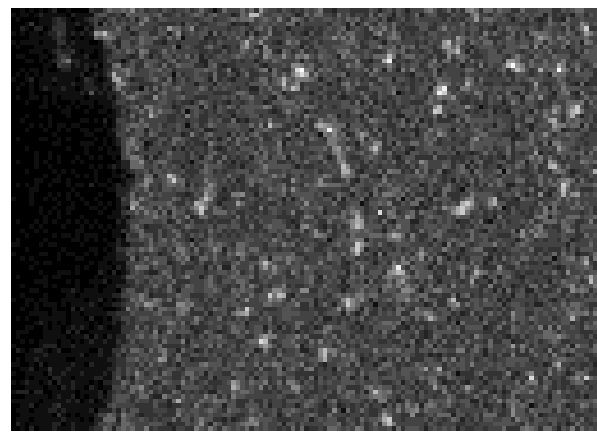

(c) Cr Mapping

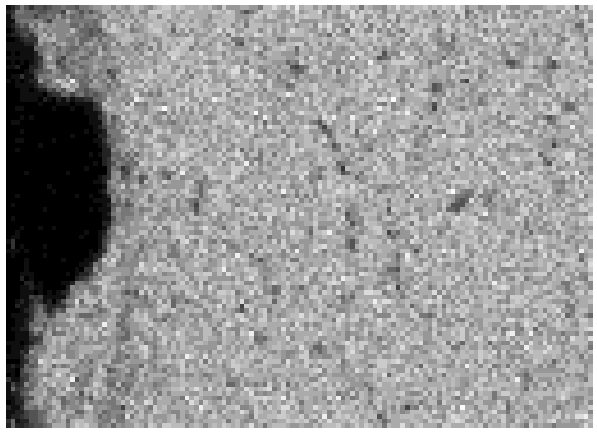

(b) Fe Mapping

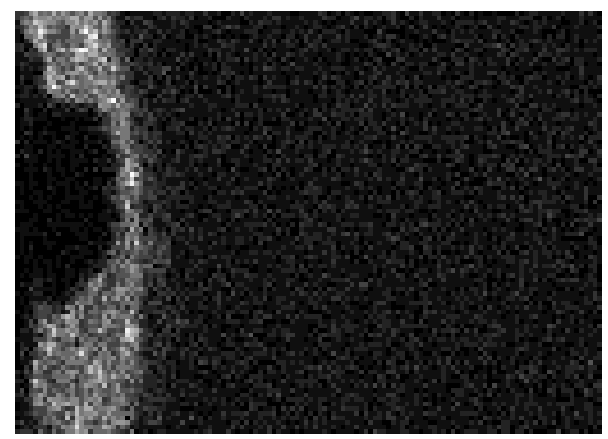

(d) Ti Mapping

Figure 3. The SEM image of Si/Ta-coated along with the distribution of $\mathrm{Fe}, \mathrm{Cr}$, and $\mathrm{Ti}$ inside the sample 


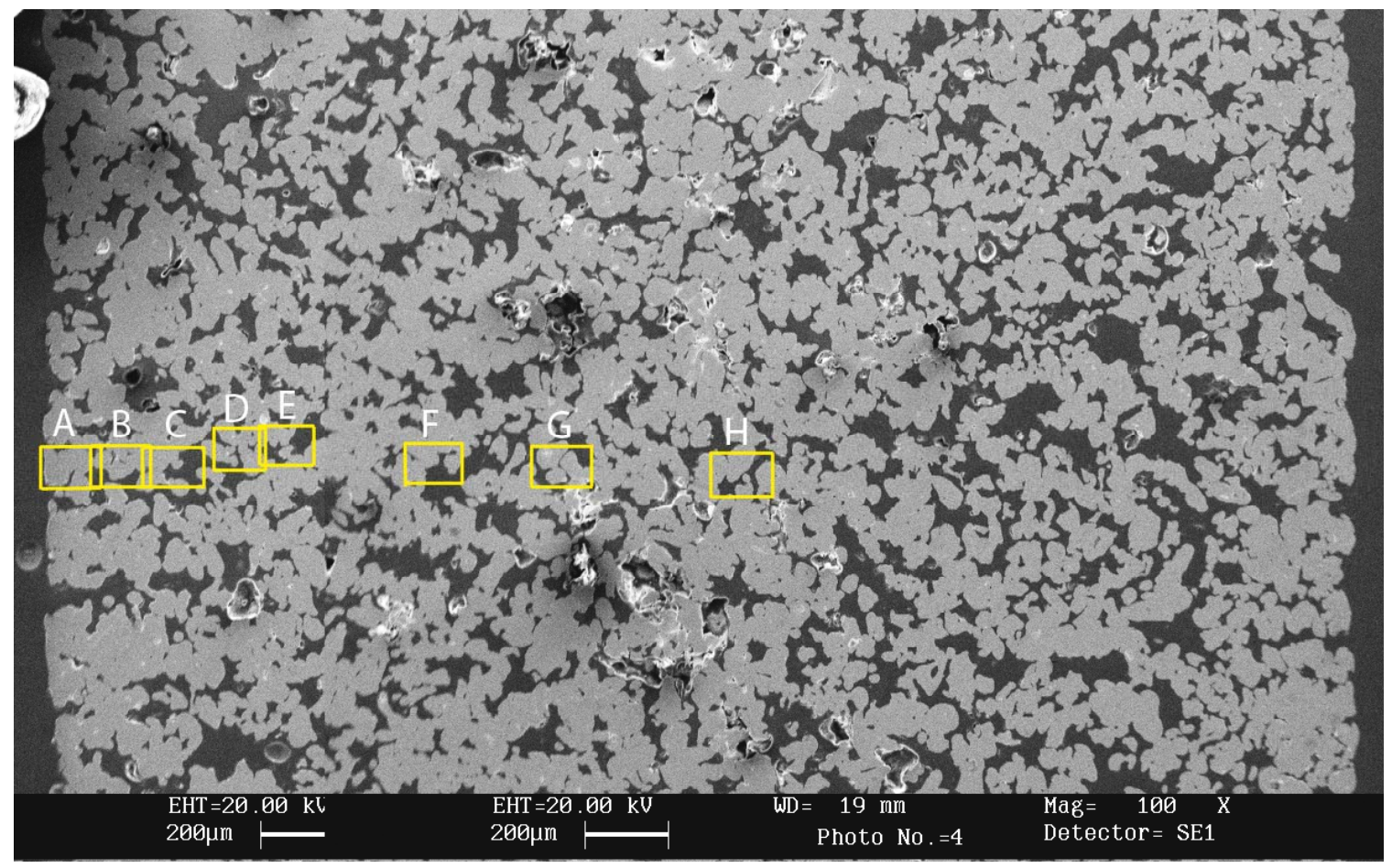

Figure 4. SEM image of the porous SS 316 frit.

Table 3

ELEMENTAL COMPOSITION INSIDE THE POROUS SS316 FRIT

\begin{tabular}{|c|l|l|l|l|l|l|l|l|}
\hline & \multicolumn{9}{|c|}{ Location } \\
\hline Element & \multicolumn{1}{|c|}{$\mathbf{A}$} & \multicolumn{1}{|c|}{ B } & \multicolumn{1}{|c|}{$\mathbf{C}$} & \multicolumn{1}{|c|}{ D } & \multicolumn{1}{|c|}{ E } & \multicolumn{1}{|c|}{ F } & \multicolumn{1}{|c|}{ G } & H \\
\hline $\mathrm{Ti}$ & 3.99 & 3.14 & 1.07 & 1.97 & 0.74 & $0.05^{*}$ & $0.02^{*}$ & -- \\
\hline $\mathrm{Si}$ & 2.89 & 2.73 & 1.72 & 2.18 & 2.06 & 2.17 & 1.95 & 2.12 \\
\hline $\mathrm{Fe}$ & 61.50 & 61.19 & 66.49 & 63.29 & 64.79 & 68.09 & 67.89 & 67.37 \\
\hline $\mathrm{Cr}$ & 18.57 & 20.12 & 18.69 & 20.57 & 20.42 & 17.95 & 17.32 & 17.99 \\
\hline $\mathrm{Ni}$ & 10.58 & 11.02 & 10.37 & 10.91 & 10.78 & 10.56 & 12.05 & 10.93 \\
\hline $\mathrm{Mo}$ & 1.21 & 1.19 & 1.21 & 1.08 & 1.21 & 1.18 & 0.77 & 1.58 \\
\hline $\mathrm{Cl}$ & 1.25 & 0.62 & 0.45 & -- & -- & -- & -- & - \\
\hline
\end{tabular}


Figure 5a illustrates a magnified image of one of the particles at location B shown in Figure 4 inside the porous frit. As shown in Figure 5C, titanium is present mainly on the outer edge of each of the metal particles. The level of Si is too low to show its distribution precisely in this map. We believe that $\mathrm{Si}$ is also coated only at the outer edges of the particles.

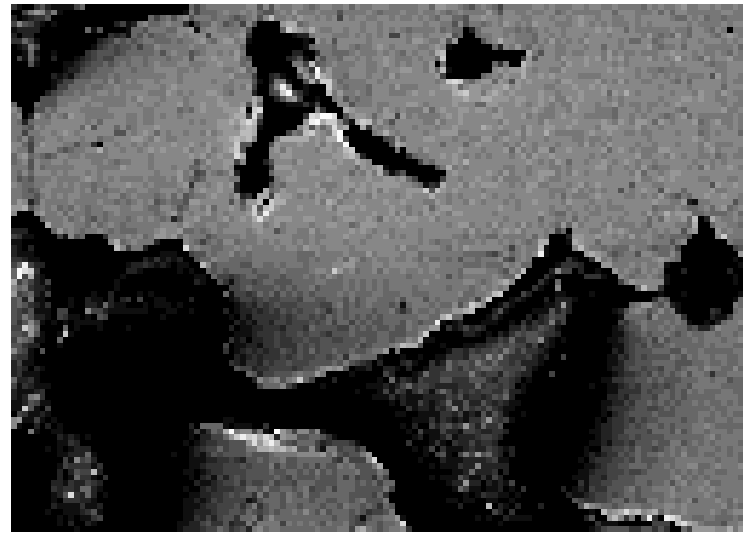

(a) SEM Image

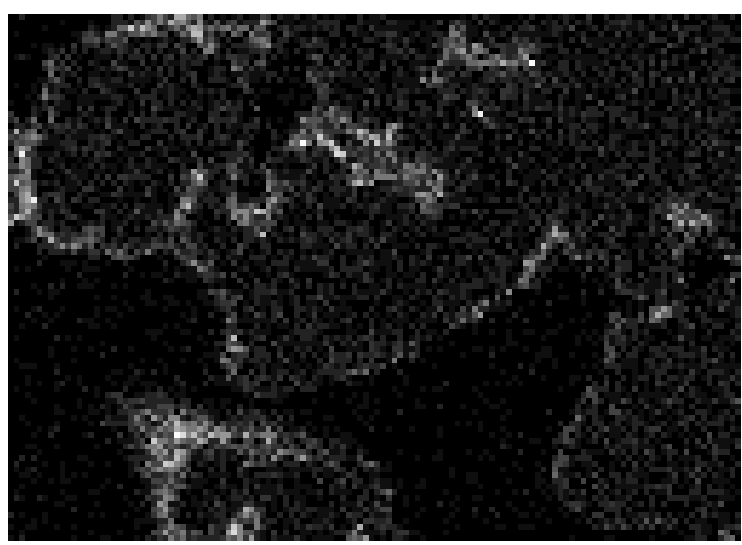

(c) Ti Mapping

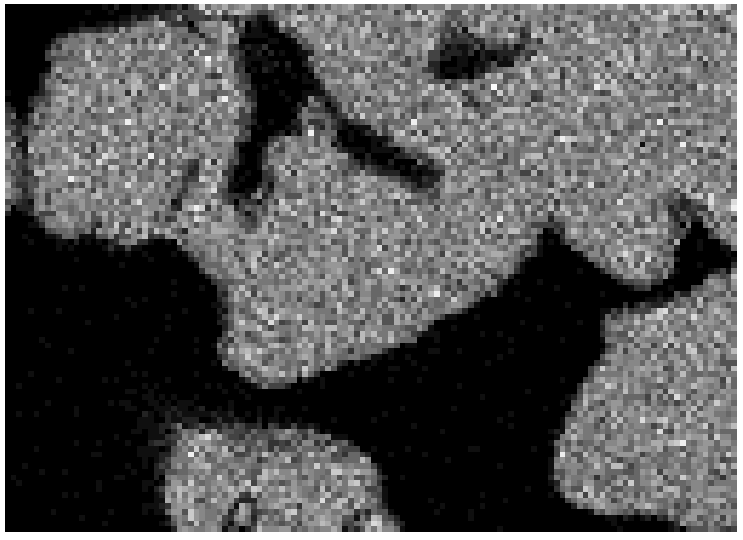

(b) Fe Mapping

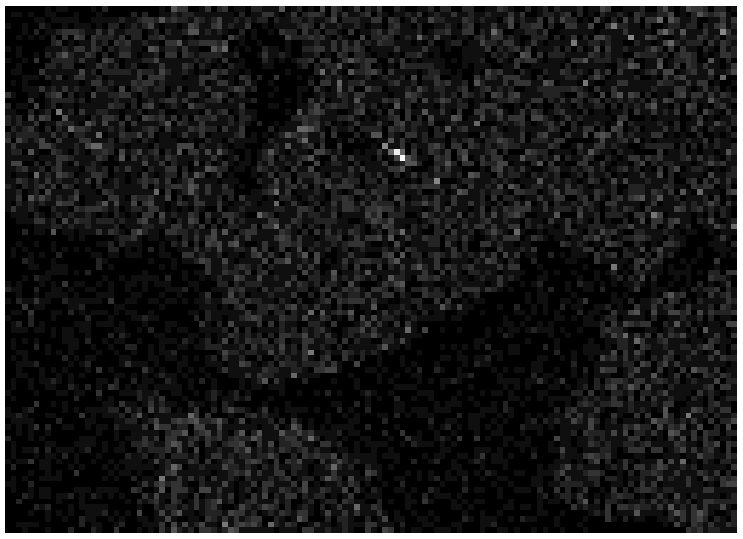

(d) Si Mapping

Figure 5. A magnified image of porous SS frit and the distribution of Ti inside the frit. (Note: The data is taken at location B shown in Figure 4).

During this period we had met with Dr. A. Tsang of Conoco Phillips at the WREL facility in Terre Haute, In, and learnt that the gasifier will be shutdown for scheduled maintenance. This shutdown represented a window of opportunity to place some of the coated samples in the actual gasifier stream, and though we had not yet tested the coatings we had prepared in our laboratory, we nevertheless sent a number of pairs of coated and uncoated samples to WREL. Table 4 lists those samples. 
Table 4

SAMPLES SENT FOR GASIFIER EXPOSURE TESTS

\begin{tabular}{|c|c|c|c|c|c|}
\hline Coupon \# & Size (mm) & Marking & Alloy & Coating & Run No. \\
\hline 1 & $31 \times 27 \times 3.5$ & None & Porous 316 & TiN, TaN & 47 \\
\hline 2 & $50 \times 25 \times 3.5$ & None & Porous 316 & $\mathrm{Cr}$ & 41 \\
\hline 3 & $55 \times 25 \times 3.5$ & None & Porous 316 & $\mathrm{Si} / \mathrm{TiN}$ & 50 \\
\hline 4 & $14 \times 52 \times 9.7$ & None & 409 & $\mathrm{Cr}$ & 49 \\
\hline 5 & $51 \times 19 \times 3.5$ & $405-11$ & 405 & $\mathrm{Cr}$ & 49 \\
\hline 6 & $51 \times 19 \times 3.5$ & $\begin{array}{c}304 \\
\text { A4074 } \\
\text { A0765 }\end{array}$ & 304 & $\mathrm{Cr}$ & 42 \\
\hline 7 & $51 \times 19 \times 3.5$ & $\begin{array}{c}410 \\
\text { HTT } 478 \\
\text { B0154 } \\
\end{array}$ & 410 & $\mathrm{Cr}$ & 48 \\
\hline 8 & $51 \times 19 \times 3.5$ & 410-09 & 410 & $\mathrm{Si} / \mathrm{TiN}$ & 50 \\
\hline
\end{tabular}

\section{CONCLUSIONS AND FUTURE WORK}

The fluidized-bed chemical vapor deposition technique was used to coat a number of samples of different compositions with $\mathrm{Cr} / \mathrm{Al}, \mathrm{Ti} / \mathrm{Ta}$, or $\mathrm{Si} / \mathrm{TiN}$. During the next quarter, we will samples in simulated gasifier atmosphere in our laboratory. 